\title{
General Dentists and Special Needs Patients: Does Dental Education Matter?
}

\author{
Loan P. Dao, B.S.; Samuel Zwetchkenbaum, D.D.S.; Marita Rohr Inglehart, Dr.phil.habil. \\ Abstract: Special needs patients are one of the underserved dental patient groups in the United States. This study investigates \\ whether undergraduate dental education about special needs patients affects general dentists' a) professional behavior, b) practice \\ characteristics, and c) attitudes concerning special needs patients. Data were collected from 208 general dentists (178 male/30 \\ female; average age: 49.85 years) who were members of the Michigan Dental Association. The more the respondents agreed that \\ dental education had prepared them well, the more likely they were to treat various types of special needs patients and to set up \\ their practices so they could treat them and the more they liked treating these patients. In conclusion, most general dentists did \\ not think their undergraduate dental education had prepared them well to treat special needs patients. However, the better they \\ reported to have been educated, the more likely they were to treat special needs patients. Given the access to care problems for \\ many special needs patients, it seems crucial to revise dental curricula and provide more didactic and clinical education concern- \\ ing the treatment of special needs patients.
}

\begin{abstract}
Mr. Dao is a student in the School of Dentistry; Dr. Zwetchkenbaum is Clinical Assistant Professor II and Program Director, General Practice Residency in Hospital Dentistry; and Dr. Inglehart is Associate Professor of Dentistry, Department of Periodontics and Oral Medicine, School of Dentistry and Adjunct Associate Professor of Psychology, Department of Psychology, College of Literature, Science, and Arts — all at the University of Michigan. Direct correspondence and requests for reprints to Dr. Marita Rohr Inglehart, Department of Periodontics and Oral Medicine, School of Dentistry, University of Michigan, Ann Arbor, MI 48109-1078; 734-763-8073 phone; 734-763-5503 fax; mri@umich.edu.
\end{abstract}

Key words: special needs patients, disabilities, general dentists, dental education, professional behavior, practice characteristics, attitudes concerning special needs

Submitted for publication 3/10/05; accepted 6/7/05

$\mathrm{S}$ pecial care dentistry is the delivery of dental care tailored to the individual needs of patients who have disabling medical conditions or mental or psychological limitations that require consideration beyond routine approaches. ${ }^{1}$ Research showed that more than 50 million U.S. residentswhich equals approximately one in five U.S. citizens - have disabilities that challenge them on a daily basis. ${ }^{2}$ In order to highlight just a few issues concerning the prevalence rates of certain disabilities, it may be interesting to consider the following statistics. While children between five and fifteen years of age with a disability accounted for only 5.8 percent of this population, the relative percentages increased over the life span to 18.6 percent of adults with disabilities between sixteen and sixty-four years of age and to 41.9 percent of adults aged sixty-five years and older. ${ }^{3}$ Special needs cover a wide range of issues. Among the noninstitutionalized, civilian U.S. population aged five years and older, approximately 21.2 million persons reported conditions that limited their physical activities (such as walking, climbing stairs, lifting, or reaching), 12.4 million individuals reported physical, mental, or emotional conditions causing difficulties in learning, remembering, or concentrating, and 9.3 million persons re- ported sensory disabilities including sight and hearing. ${ }^{3}$ It is predicted that by 2030 , one in five adults in the United States will be at least sixty-five years of age and that there will be an increase in the number of special needs patients. ${ }^{1}$

Given these high percentages of individuals with special needs in the United States, it is not surprising that, on July 30, 2004, the Commission on Dental Accreditation adopted new standards for dental and dental hygiene education programs to ensure that future dental professionals will be better prepared to care for special needs patients. ${ }^{4}$ In addition, in March 2005, the House of Delegates of the American Dental Education Association (ADEA) $)^{5}$ at the annual ADEA Meeting in Baltimore, MD, accepted Resolution 18-H-2004 supporting these efforts. One underlying assumption of these required educational standards clearly is that these changes will contribute to reducing the disparities in oral health status and access to oral health care between patients with special needs and patients without special needs. The extent of these disparities was carefully documented in the U.S. surgeon general's report on oral health. ${ }^{6}$ The objectives of our research were to explore the role of dental education in this context. 


\section{Dental Education}

\section{Concerning the Treatment of Special Needs Patients}

Efforts to improve undergraduate dental education concerning the treatment of special needs patients date back to the 1970s when the Robert Wood Johnson Foundation provided large grants to eleven dental schools in the United States over a four-year period for the development of teaching programs for patients with handicapping conditions. ${ }^{7}$ The American Association of Dental Schools (AADS; now ADEA) proposed a set of curriculum guidelines for teaching predoctoral students about treating patients with "handicapping" conditions around this time as well. ${ }^{8}$ Despite these efforts, a survey of U.S. and Canadian dental schools conducted by the Academy of Dentistry for Persons with Disabilities in 1993 showed that the average number of lectures about the management of patients with disabilities was 12.9 hours and the average clinical instruction was 17.5 hours per dental student. Thirty-two schools reported less than ten hours in their curricula. ${ }^{9}{ }^{90}$ A follow-up survey in 1999 documented that there was actually a decrease in the time spent in the predoctoral dental curriculum on educating students about the treatment of special needs patients. Fifty-three percent of dental schools reported that they had less than five hours of didactic training in their curricula, and in 73 percent of the schools the clinical instruction concerning the care of special needs patients consisted of only between 0 and 5 percent of a student's time. ${ }^{11,12}$ A recent survey with third- and fourth-year students in five dental schools showed that the situation has not significantly improved since $1999 .{ }^{13}$ Approximately half of the fourth-year dental students (50.8 percent) reported for example that they had never provided any treatment for patients with mental retardation, and more than one in five students (22.2 percent) indicated that they had less than one hour of didactic presentations concerning these patients. One question addressed in this study is therefore how well the respondents' undergraduate dental education had prepared these providers to treat special needs patients.

There are obviously many factors that affect dental practitioners' willingness to provide care for special needs patients. ${ }^{14}$ However, understanding the role of undergraduate dental education concerning the treatment of special needs patients could be important when considering curricular changes to comply with new accreditation standards in the future. Specifically, it may be interesting to understand how dental education concerning the treatment of special needs patients affects various outcomes such as a) practitioners' actual behavior, b) their practice characteristics, and c) their attitudes concerning the treatment of special needs patients.

Dental Education and Professional Behavior Concerning Special Needs Patients. Research conducted in the 1970s showed that students' educational experiences, and especially their exposure to clinical situations, classroom instruction, and multidisciplinary teams, were closely related to their acceptance of patients with handicapping conditions after their graduation from dental school. ${ }^{15}$ Recent studies with dental practitioners ${ }^{16}$ and dental students ${ }^{13}$ reiterated these earlier findings and provided support for the hypothesis that dental education concerning the treatment of special needs patients has an effect on practitioners' professional behavior and dental students' willingness to consider providing care for these patients. In addition to assessing globally whether practitioners are willing to treat special needs patients, it seems important to understand the extent to which they are willing to not only treat adult special needs patients, but also children with special needs ${ }^{16}$ and to which they are willing to treat patients with different types of disabilities. Research showed that patients with certain types of disabilities (such as motion impairments) were more likely to have access to dental care than patients with other disabilities (such as mental retardation).${ }^{17}$ This study therefore explored how dental education affected how many adult and pediatric patients with various types of disabilities the respondents treated.

Dental Education and Practice Characteristics Concerning Special Needs Patients. Financial difficulties and problems with physical access for patients with impaired motor skills were cited as reasons why access to dental care for the special needs patient population might be limited. ${ }^{18}$ One study conducted in 1997 showed, for example, that 56 percent of dental practices surveyed had steps or stairs to their entrance and that only 9 percent had a ramp or lift to the entrance. ${ }^{19}$ Only one quarter of practices surveyed in a study conducted in 2002 reported having full physical access for all patients. ${ }^{20}$ In addition to problems with physical access, problems with not finding knowledgeable dental staff were also reported 
as a barrier to providing care for special needs patients. ${ }^{21}$ Dental hygienists can play a significant role in the prevention, recognition, and treatment of oral diseases for special needs patients. ${ }^{22}$ Knowledgeable staff who are comfortable with treating special needs patients is an absolutely crucial component of a dental team that provides care for special needs patients. This study explored therefore whether dentists with more positive educational experiences were more likely to have their practice set up in a way that they can treat special needs patients and had staff that were more knowledgeable and comfortable with treating special needs patients.

Dental Education and Confidence/Attitudes Concerning Treating Special Needs Patients. Research on the effect of dental education about special needs patients on students' and practitioners' confidence and attitudes concerning treating these patients has a long tradition. In 1979, the National Conference on Dental Care for Handicapped Americans $^{23}$ reported that a lack of education and experience in the treatment of special needs patients might cause negative attitudes towards the "handicapped." A study conducted in 1980 showed that students who participated in an extramural program and treated mentally retarded patients had more confidence and felt more relaxed about handling the mentally retarded in their dental practice. ${ }^{24}$ Participation in this program gave students the opportunity to confront their fears and anxieties about working with handicapped patients and led to more positive attitudes towards these patients. Positive changes in students' attitudes and their level of confidence concerning the treatment of special needs patients were also found in other extramural programs ${ }^{25}$ and in studies of the effects of hands-on experiences in educational settings. ${ }^{26}$

Research conducted more recently showed that the more experience students had with patients with mental retardation, the greater their awareness of the capabilities of people with mental retardation, the more positive their attitudes, and the better their appreciation of these patients' dental needs..$^{13}$ This study revisited this question and explored whether dentists with more positive educational experiences were more likely to have more confidence when treating these patients and to have more positive attitudes.

\section{Materials and Methods}

The IRB for the Health Sciences at the University of Michigan approved this research (\#H04-
00004385). No signed informed consent form was required according to the IRB approval because the dentists who responded to this mailed survey did so anonymously and had received an explanation of the purpose of the research and their rights as research subjects in the mailing. The anonymous mailed response was interpreted as implicit consent to participate in the study.

A sample of 500 general dentists was randomly chosen from the list of approximately 7,000 members of the Michigan Dental Association (MDA). A self-administered survey was mailed to these practitioners. The response rate was 41.3 percent $(\mathrm{N}=208)$. The majority of the respondents were male ( 178 male vs. 30 female) and white (white: 184; African American: 6; Hispanic: 5; Native American: 4; Asian American: 1). The average age was 49.85 years (range: twenty-seven to eighty-three years). The respondents had practiced dentistry on average for approximately twenty-three years (range: one to fiftyfour years).

A self-administered survey was mailed in July 2004 to the random sample. A cover letter from the dean of the University of Michigan School of Dentistry explained the purpose of the survey and the recipients' rights as research subjects and asked for their cooperation with the study. A self-addressed stamped envelope was included in the mailing. The survey asked questions concerning which adult and pediatric special needs patients the dentists treated, which treatment they provided for these patients, and which special arrangements they made to be able to treat these patients. Questions concerning the dentists' educational background, personal experiences, and attitudes concerning the treatment of special needs patients were included as well.

\section{Results}

\section{Types of Child and Adult Special Needs Patients Treated}

Overall, 22.7 percent of the respondents ( $\mathrm{N}=41)$ reported not treating any adult special needs patients, and 51.6 percent $(\mathrm{N}=94)$ not treating any pediatric patients with special needs in an average week. However, when asked whether they would treat adult and pediatric patients with nine different disabilities (motion impaired, hearing impaired, vision impaired, 
mental retardation, autism, cerebral palsy, neurological disorder, Alzheimer's disease/dementia, and closed head injury), the percentages of dentists who were willing to treat these patients differed depending on the age of the patient (adult vs. child) and the type of disability. For every single type of disability other than autism, the percentage of respondents indicating that they treated adult patients was significantly higher than the percentage of respondents indicating that they treated pediatric patients with a certain disability. Concerning adult patients, patients with motion impairment were accepted by the highest percentage of dentists ( 87.2 percent), followed by patients with hearing impairments ( 84.9 percent), patients with Alzheimer's disease/dementia (76.4 percent), patients with vision impairments (75.9 percent), and mental retardation (70.8 percent). Adult patients with autism were accepted by the lowest percentage of general practitioners (33 percent), followed by patients with cerebral palsy ( 40.6 percent) and closed head injury (43.9 percent).

Concerning providing access to care for pediatric patients, the percentages of acceptance were lower. Child patients with hearing impairments were most likely to be accepted ( 66 percent), followed by child patients with motion impairment (62.6 percent), mental retardation (59 percent), and vision impairment (56.1 percent). Children with autism (40.1 percent acceptance), cerebral palsy (36.3 percent), neurological disorders (34 percent), and closed head injury (25.5 percent) were least likely to be accepted as patients by the respondents.

\section{Perceived Quality of Dental Education Concerning Treating Special Needs Patients}

The respondents answered three questions on the quality of their undergraduate dental education concerning treating special needs patients. Questions 1 and 2 asked, "How well did your undergraduate dental education prepare you to treat special needs patients/patients with mental retardation?" Question 3 asked them to indicate their agreement with the statement "Dental school prepared me well to treat special needs patients." The Cronbach alpha reliability index for these three items was .947, indicating that there was a high inter-item consistency in the responses to these questions. As can be seen in Table 1 , the majority of respondents either felt they were not at all well prepared or not well prepared to treat patients with special needs (25.9 percent/33.8 percent) or patients with mental retardation (26.4 percent/37.8 percent). Only small percentages of respondents agreed that they had been very well or well prepared to treat special needs patients (1.8 percent/ 10.4 percent) or patients with mental retardation (1.6 percent $/ 8.5$ percent), or strongly agreed or agreed with the statement that dental school had prepared them well (3.9 percent/7.3 percent).

\begin{tabular}{|c|c|c|c|c|c|c|}
\hline \multirow{2}{*}{$\begin{array}{l}\text { Items } \\
\text { How well did your undergraduate } \\
\text { dental education prepare you for: }\end{array}$} & \multicolumn{5}{|c|}{ Answer Categories } & \multirow{2}{*}{$\begin{array}{c}\text { Mean } \\
\text { Values*** }\end{array}$} \\
\hline & $\stackrel{1}{\text { not at all well }}$ & $\stackrel{2}{\text { not well }}$ & 3 & $\begin{array}{c}4 \\
\text { well }\end{array}$ & $\begin{array}{c}5 \\
\text { very well }\end{array}$ & \\
\hline $\begin{array}{l}\text { - managing patients with } \\
\text { special needs }\end{array}$ & $\begin{array}{c}52 * \\
(25.9 \%)^{* *}\end{array}$ & $\begin{array}{c}68 \\
(33.8 \%)\end{array}$ & $\begin{array}{c}52 \\
(25.9 \%)\end{array}$ & $\begin{array}{c}21 \\
(10.4 \%)\end{array}$ & $\begin{array}{c}8 \\
(1.8 \%)\end{array}$ & 2.33 \\
\hline \multirow[t]{2}{*}{$\begin{array}{l}\text { - managing patients with } \\
\text { mental retardation }\end{array}$} & $\begin{array}{c}53 \\
(26.4 \%)\end{array}$ & $\begin{array}{c}76 \\
(37.8 \%)\end{array}$ & $\begin{array}{c}48 \\
(23.9 \%)\end{array}$ & $\begin{array}{c}17 \\
(8.5 \%)\end{array}$ & $\begin{array}{c}7 \\
(1.6 \%)\end{array}$ & 2.25 \\
\hline & $\begin{array}{c}1 \\
\text { disagree strongly }\end{array}$ & $\begin{array}{c}2 \\
\text { disagree }\end{array}$ & 3 & $\begin{array}{c}4 \\
\text { agree }\end{array}$ & $\begin{array}{c}5 \\
\text { agree strongly }\end{array}$ & \\
\hline $\begin{array}{l}\text { Dental school prepared me well } \\
\text { for treating special needs patients. }\end{array}$ & $\begin{array}{c}59 \\
(28.6 \%)\end{array}$ & $\begin{array}{c}68 \\
(33 \%)\end{array}$ & $\begin{array}{c}56 \\
(27.2 \%)\end{array}$ & $\begin{array}{c}15 \\
(7.3 \%)\end{array}$ & $\begin{array}{c}8 \\
(3.9 \%)\end{array}$ & 2.25 \\
\hline \multicolumn{7}{|c|}{$\begin{array}{l}*=\text { frequencies of responses } \\
* *=\text { percentage of respondents } \\
* * *=\text { average answers of the responses provided on the answer scale ranging from } 1=\text { "not at all well" to } 5=\text { "very well" }\end{array}$} \\
\hline
\end{tabular}




\section{Effects of Dental Education in Treating Special Needs Patients}

To assess the effect of general dentists' perceptions of their dental education on their professional behavior, practice characteristics, and confidence levels/attitudes toward special needs patients, univariate analyses of variance were conducted with the independent variable "Quality of education." Respondents who had strongly disagreed or disagreed with the item "Dental school prepared me well to treat special needs patients" were grouped into a category of "negative educational experience"; those respondents who had strongly agreed or agreed with this statement were grouped into a category "positive educational experience"; and respondents who had chosen the neutral answer (" 3 " on five-point scale) were grouped into a category of "neutral experience."

Dental Education and Professional Behavior. As can be seen in Table 2, significant effects were found for the dependent variables "Percentage of patients from low socioeconomic backgrounds" $(p=.021)$ and "Number of pediatric special needs patients treated during an average week." The means were in the predicted direction. While respondents who were well prepared treated on average 2.05 pediatric special needs patients per week, the respondents who were not well prepared treated on average only .74 special needs children per week. Concerning the treatment of adult special needs patients, no significant effect was found for the number of adult special needs patients treated in an average week. However, a sum score was computed by adding how many adult and child patients with different types of disabilities the respondents indicated they would treat. This sum score ranged from "0" (which indicated that they did not treat any adult or child patient with any of the disabilities) to "17" (which would indicate that they treated adults with all nine types of disabilities listed and child patients with all eight types of disabilities listed). As can be seen in Table 2, while the respondents who felt well educated treated on average 10.83 different types of patients, the respondents who did not feel well edu-

Table 2. Average responses concerning professional behavior, practice characteristics, and attitudes concerning treating special needs patients by dentists who perceived their education about these issues to have been negative, neutral, or positive

\begin{tabular}{|c|c|c|c|c|}
\hline \multirow[t]{2}{*}{ Professional Behavior } & \multicolumn{3}{|c|}{$\begin{array}{c}\text { Dental Education About Special } \\
\text { Needs Patients Was }\end{array}$} & \multirow[b]{2}{*}{ p-value } \\
\hline & Negative* & Neutral & Positive & \\
\hline Percentage of patients from low socioeconomic background & $17.38 \%$ & $25.29 \%$ & $25.00 \%$ & $<.05$ \\
\hline Percentage of patients covered by Medicaid & $3.71 \%$ & $9.24 \%$ & $11.14 \%$ & $<.10$ \\
\hline Number of adult special needs patients treated during an average week & 1.85 & 1.83 & 1.95 & n.s. \\
\hline Number of pediatric special needs patients treated during an average week & .74 & 1.23 & 2.05 & $<.05$ \\
\hline Sum score of patient groups treated** & 8.93 & 10.69 & 10.83 & $<.10$ \\
\hline \multicolumn{5}{|l|}{ Practice Characteristics ${ }^{* * *}$} \\
\hline My practice is not set up for the treatment of special needs patients. & 3.15 & 2.67 & 2.92 & $<.01$ \\
\hline My staff is comfortable treating special needs patients. & 3.06 & 3.23 & 3.92 & $<.000$ \\
\hline My staff is knowledgeable in treating special needs patients & 2.76 & 3.29 & 3.75 & $<.000$ \\
\hline \multicolumn{5}{|l|}{ Professional Attitudes*** } \\
\hline I like to treat adult special needs patients. & 2.64 & 3.02 & 3.72 & $<.000$ \\
\hline I am confident treating special needs patients. & 3.17 & 3.56 & 3.96 & $<.01$ \\
\hline
\end{tabular}

\footnotetext{
*Responses to the statement "Dental school prepared me well for treating special needs patients" were given on a five-point scale ranging from $1=$ "disagree strongly" to $5=$ "agree strongly." The category "negative" consists of respondents who answered with a " 1 " (disagree strongly) or "2" (disagree); the category "neutral" consists of respondents who answered with a " 3 "; and the category "positive" of respondents who answered with a "4" (agree) or "5" (agree strongly).

**This sum score was determined by adding the groups of pediatric and adult patients with nine types of disabilities (motion impaired, hearing impaired, vision impaired, mental retardation, autism, cerebral palsy, neurological disorder, Alzheimer's/ dementia, and closed head injury) the respondents treated. The score could range from 0 to 17 (because there are no children with Alzheimer's disease).

*** Responses to the statements concerning practice characteristics and professional attitudes were given on a five-point scale ranging from 1 = "disagree strongly" to 5 = "agree strongly."
} 
cated treated on average 8.93 different types of patients $(\mathrm{p}=.078)$.

As can be seen in Table 3, the perceived quality of dental education about special needs patients correlated significantly with the percentages of patients from lower socioeconomic background and of patients covered by Medicaid and the number of pediatric special needs patients the dentists treated as well as the variety of patients with various disorders.

Dental Education and Practice Characteristics. The respondents also indicated how much they agreed with statements concerning how well their practice was set up for treating special needs patients and how knowledgeable and comfortable their staff were with treating special needs patients. As can be seen in Table 2, respondents who felt well educated were significantly less likely to agree with a statement that their practice was not set up for treating special needs patients and were significantly more likely to agree that their staff were knowledgeable and comfortable treating special needs patients than dentists who felt not well prepared to treat special needs patients. The correlations between the responses to the three items about the quality of dental education concerning special needs patients and these practice characteristic items were significant and quite high (see Table 3).

Dental Education and Confidence/Attitudes Toward Special Needs Patients. The respondents also indicated how much they agreed with statements that

Table 3. Correlations between answers concerning dental education and professional behavior, practice characteristics, and attitudes concerning treating special needs patients

Undergraduate education prepared me well Dental school to treat patients with prepared me well*

special needs* mental retardation*

\section{Professional Behavior}

Percentage of patients from low socioeconomic background

$\begin{array}{ccc}.193 & .186 & .167 \\ \mathrm{p}<.01 & \mathrm{p}<.01 & \mathrm{p}<.05 \\ .142 & .162 & .139 \\ \mathrm{p}<.05 & \mathrm{p}<.05 & \mathrm{p}<.10 \\ -.001 & .003 & .014 \\ \text { n.s. } & \text { n.s. } & \text { n.s. } \\ .184 & .177 & .149 \\ \mathrm{p}<.05 & \mathrm{p}<.05 & \mathrm{p}<.05 \\ .151 & .205 & .132 \\ \mathrm{p}<.05 & \mathrm{p}<.01 & \mathrm{p}<.10\end{array}$

Percentage of patients covered by Medicaid

Number of adult special needs patients treated during an average week

Number of pediatric special needs patients treated during an average week

Sum score of patient groups treated**

$\mathrm{p}<.05$

$\mathrm{p}<.01$

$\mathrm{p}<.10$

\section{Practice Characteristics ${ }^{* * *}$}

My practice is not set up for the treatment of special needs patients.

My staff are comfortable treating special needs patients.

$-.274$

$\mathrm{p}<.001$

.332

$\mathrm{p}<.001$

.427

My staff are knowledgeable in treating special needs patients.

\section{Professional Attitudes***}

I like to treat adult special needs patients.

I am confident treating special needs patients. $\mathrm{p}<.001$

.349
$p<.001$
.259
$p<.001$

$\begin{array}{cc}-.214 & -.227 \\ \mathrm{p}<.01 & \mathrm{p}<.01 \\ .306 & .303 \\ \mathrm{p}<.001 & \mathrm{p}<.001 \\ .452 & .443 \\ \mathrm{p}<.001 & \mathrm{P}<.001\end{array}$

.349
$p<.001$
.286
$p<.001$

*Responses to the statement "Dental school prepared me well for treating special needs patients" were given on a five-point scale ranging from $1=$ "disagree strongly" to $5=$ "agree strongly." The category "negative" consists of respondents who answered with a "1" (disagree strongly) or "2" (disagree); the category "neutral" consists of respondents who answered with a " 3 "; and the category "positive" of respondents who answered with a "4" (agree) or "5" (agree strongly).

**This sum score was determined by adding the groups of pediatric and adult patients with nine types of disabilities (motion impaired, hearing impaired, vision impaired, mental retardation, autism, cerebral palsy, neurological disorder, Alzheimer's/ dementia, and closed head injury) the respondents treated. The score could range from 0 to 17 (because there are no children with Alzheimer's disease).

***Responses to the statements concerning practice characteristics and professional attitudes were given on a five-point scale ranging from 1 = "disagree strongly" to $5=$ "agree strongly." 
they liked to treat special needs patients and were confident treating special needs patients. As can be seen in Table 2, the quality of dental education had a significant effect on the responses to these statements. Dentists who felt well prepared were significantly more positive towards treating special needs patients and significantly more confident when providing treatment than dentists who responded neutrally or negatively to the dental education statement. The responses to all three education items correlated significantly with the responses to the items inquiring about the degree to which the dentists liked to treat special needs patients $(\mathrm{r}=.349 ; \mathrm{r}=.349 ; \mathrm{r}=.374)$ and were confident when treating them $(\mathrm{r}=.259 ; \mathrm{r}=.286$; $\mathrm{r}=.263)$ (see Table 3).

\section{Discussion}

Half a century ago, Castaldi wrote in an article in the Journal of Dental Education that "a course of study in dental care for handicapped children was relatively new to the dental school curriculum. ${ }^{{ }^{27} \mathrm{~A}}$ quarter century ago, at the 1979 National Conference on Dental Care for Handicapped Americans, the lack of trained dental professionals who could provide care for special needs patients was openly discussed. ${ }^{23}$ However, despite all efforts made by ADEA to develop curriculum guidelines, ${ }^{8,28}$ and despite all efforts of dental school faculty to publish editorials ${ }^{29}$ and position ${ }^{30}$ and research ${ }^{16,22,25}$ papers in the Journal of Dental Education over the years, progress seems to be slow. The 2002 ADEA survey of dental school seniors reported that almost 41 percent of responding students indicated that they were less than or not well enough prepared to provide care for patients with disabilities. ${ }^{31}$ And a recently published study showed that the second highest proportion of students (after practice management) indicated that they had received inadequate experience and training in dental school for the care of patients with disabilities. ${ }^{13}$ This lack of a solid education on how to treat special needs patients is also supported by the data found in this study. A majority of the respondents did not perceive that their undergraduate education had prepared them well to treat special needs patients. As a matter of fact, the respondents' age was significantly and negatively correlated with the respondents' perceptions of the quality of their undergraduate dental education about treating spe- cial needs patients. The younger the dentists, the worse they evaluated their dental education concerning special needs patients $(\mathrm{r}=-.207 ; \mathrm{p}=.003)$ and concerning treating patients with mental retardation $(\mathrm{r}=-.164 ; \mathrm{p}=.02)$. It is possible to argue that the respondents in this survey were all from Michigan. However, findings from national surveys ${ }^{16}$ support the conclusion that there is a need for improvement of undergraduate dental education programs, especially when considering the new accreditation standards. ${ }^{4}$ A national survey assessing the quality of dental education concerning the treatment of special needs patients in classroom settings, school-based clinics, and community settings would definitely make a worthwhile contribution to gaining a better understanding of the status quo of dental education concerning these issues.

However, our data suggest that a revision of the curriculum concerning special needs patients would make a difference in how future providers practice their profession, set up their practices, train their staff, and feel about treating special needs patients. Such changes could then make a difference in the long run for reducing oral health disparities and increasing access to dental care for all individuals. The finding that there were significant relationships between how well the respondents had been prepared by their undergraduate dental education to treat special needs patients and patients with mental retardation and the percentage of patients from lower socioeconomic background, the number of special needs children they reported to treat, and the variety of patients with special needs for whom they provided services should be encouraging to each dental educator who works in this area. The data clearly suggest that solid dental education can make a difference in this domain.

It is obvious that many factors such as a patient's ability to pay and the amount of time needed to treat a patient will play a role in a dentist's decision to treat special needs patients. However, providing a solid knowledge and skills basis will improve dentists' attitudes towards treating these patients and will give them more confidence. Such positive attitudes may then allow them to think about overcoming obstacles that may keep them from treating these patients such as the set up of their practice and hiring or training their staffs to provide the support they would need to include these patients in their patient families. 


\section{Conclusions}

1. The majority of respondents did not perceive that their undergraduate dental education concerning the treatment of special needs patients had prepared them well. Major efforts need to be made to improve dental education concerning these patient groups.

2. Dentists who felt well prepared were a) more likely to treat pediatric special needs patients and b) to provide services for patients with more diverse special needs than dentists who did not feel well prepared.

3. The better dentists felt prepared to treat special needs patients: a) the more likely they were to set up their practice so that special needs patients could be treated, and $b$ ) the more positive they evaluated their staff's abilities and level of comfort when providing care for special needs patients.

4. The better dentists felt prepared to treat special needs patients: a) the more positive their attitudes towards treating these patients, and b) the more confident they were when treating these patients.

In summary, the question of how well dental and dental hygiene education prepares future dental providers to care for special needs patients needs to be revisited. The quality of this education has an impact on future providers' professional behavior, practice characteristics, attitudes, and confidence when treating these patients. It can ultimately contribute to reducing the disparities between special needs patients and patients without special needs' oral health and access to care. Dental education is one piece of the puzzle of how to bring oral health care to all U.S. citizens.

\section{Acknowledgments}

Mr. Dao's research was supported by an AADR Student Research Fellowship (2004). We want to thank the Michigan Dental Association for providing us with a $C D$ with the addresses of their members who are general dentists.

\section{REFERENCES}

1. Lawton L. Providing dental care for special patients: tips for the general dentist. J Am Dent Assoc 2002;133(12): 1666-70.
2. Waldman HB, Sanford JF, Perlman SP, Cinotti DA. Preparing dental graduates to provide care to individuals with special needs. J Dent Educ 2005;69(2):249-54.

3. United States census 2000. Disability status: 2000 . Census 2000 brief. Washington, DC: U.S. Department of Commerce, Economics and Statistics Administration, U.S. Census Bureau, 2000:2.

4. Commission on Dental Accreditation. Accreditation standards for dental education programs. Chicago: American Dental Association, July 30, 2004.

5. American Dental Education Association. Proceedings of the 2004 House of Delegates. Resolution 18-H-2004. J Dent Educ 2004;68(7):705.

6. Oral health in America: a report of the surgeon general. Rockville, MD: U.S. Department of Health and Human Services, 2000.

7. Campbell JT, McCaslin FC. Evaluation of a dental training program for the care of the handicapped. Spec Care Dent 1983;3(3):100-7.

8. Bentz GH, Lotzkar S. Appendix II: curriculum guidelines for dentistry for the handicapped. J Dent Educ 1979;39: $37-41$.

9. Fenton SJ. 1993 survey of training in the treatment of persons with disabilities. InterFace 1993a;9:1,4.

10. Fenton SJ. Universal access: are we ready? Spec Care Dent 1993b;13:94

11. Fenton SJ. People with disabilities need more than lip service (editorial). Spec Care Dent 1999;19:198-9.

12. Romer M, Dougherty N, Amores-Lafleur E. Predoctoral education in special care dentistry: paving the way to better access? J Dent Children 1999;66(2):132-5.

13. Wolff AJ, Waldman HB, Milano M, Perlman SP. Dental students' experiences with and attitudes toward people with mental retardation. J Am Dent Assoc 2004;135(3): 353-7.

14. Mouradian WE, Corbin SB. Addressing health disparities through dental-medical collaborations. Part II. Crosscutting themes in the care of special populations. J Dent Educ 2003;67(12):1320-6.

15. Roberts RE, et al. Dental care for handicapped children re-examined. J Public Health Dent 1978;38:22-34.

16. Casamassimo PS, Seale NS, Ruehs K. General dentists' perceptions of educational and treatment issues affecting access to care for children with special health care needs. J Dent Educ 2004;68(1):23-8.

17. Oliver CH, Nunn JH. The accessibility of dental treatment to adults with physical disabilities in northeast England. Spec Care Dent 1996;16(5):204-9.

18. Finger S, Jedrychowski J. Parents' perception of access to dental care for children with handicapping conditions. Spec Care Dent 1989;9(Dec):195-9.

19. Freeman R, Adams EK, Gelbier S. The provision of primary dental care for patients with special needs. Res Primary Dent Care 1997;4:31-4.

20. Edwards DM, Merry AJ. Disability part 2: access to dental services for disabled people. A questionnaire survey of dental practices in Merseyside. Br Dent J 2002;193(5): 253-5.

21. Charteris P, Kinsella T. The Oral Care Link: a facilitator and educator for maintaining oral health for patients at 
the Royal Hospital for neuro-disability. Spec Care Dent 2001;21(2):68-71.

22. Lemon S, Reveal M. Dental hygiene students' preparation for treatment of patients with mental illnesses. J Dent Educ 1991;55(11):724-8.

23. 1979 National Conference on Dental Care for Handicapped Americans: education programs in dentistry for the handicapped. J Dent Educ 1979;43(part 2):1-41.

24. Block MJ, Walken JW. Effect of an extramural program on student attitudes toward dental care for the mentally retarded. J Dent Educ 1980;44(3):158-61.

25. Grantham EV, Block MJ. Effect of extramural experiences on dental students' attitudes. J Dent Educ 1983;47(10): 681-4.

26. Marinelli RD, Ferguson FS, Berentsen BJ, Richardson PS. An undergraduate dental education program providing care for children with disabilities. Spec Care Dent 1991;11(3):110-2.
27. Castaldi CR. Preparation for the undergraduate student to render care for the handicapped child. J Dent Educ 1957;22:66-70.

28. Curriculum guidelines for training general practice residents to treat persons with a handicap. J Dent Educ 1990;54(5):293-6.

29. Ettinger RL, Chalmers J, Frenkel H. Dentistry for persons with special needs: how should it be recognized? J Dent Educ 2004;68(8):803-6.

30. Exhibit 10. Position Paper. Statement on the roles and responsibilities of academic institutions in improving the oral health status of all Americans. J Dent Educ 2004;68(7):759-67.

31. Weaver RG, Haden NK, Valachovic RW. Annual ADEA survey of dental school seniors: 2002 graduating class. J Dent Educ 2002;66:1388-404. 